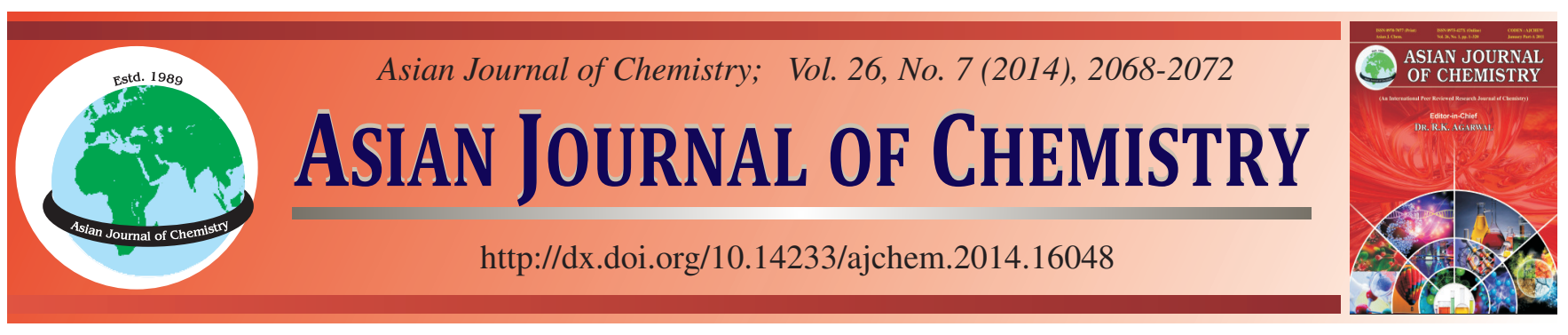

\title{
Statistical Modelling of Precipitation of Copper Ammonium Sulphite from Synthetic Copper Sulphate Solutions
}

\author{
FATIH DEMIR
}

Department of Chemical Engineering, Engineering Faculty, Ataturk University, Tr-25240 Erzurum, Turkey

Corresponding author: E-mail: fatihdemir@atauni.edu.tr

Copper ammonium sulphite was precipitated under optimum conditions by passing $\mathrm{SO}_{2}$ from a synthetic aqueous copper sulphate solution. Copper ammonium sulphite, $\mathrm{Cu}_{2} \mathrm{SO}_{3} \cdot\left(\mathrm{NH}_{4}\right)_{2} \cdot \mathrm{SO}_{3}$, was characterised by XRD. The effects of parameters such as initial concentration, $\mathrm{pH}$, stirring speed and reaction time were investigated on precipitation. A first-order model was obtained using the $2^{4}$ full factorial design method. It was observed that all parameters on the precipitation of copper ammonium sulphite were effective. The optimum conditions established for maximum copper precipitation at room temperature were: stirring speed $700 \mathrm{rpm}$, initial concentration $0.8 \mathrm{~mol} \mathrm{~L}{ }^{-1}$, $\mathrm{pH} 3.5$ and reaction time $15 \mathrm{~min}$. Under these optimum conditions, the percentage of precipitated copper from solution was 99.80.

Keywords: Precipitation, Factorial experimental design, Synthetic copper solutions, Copper ammonium sulphite.

\section{INTRODUCTION}

Obtaining copper compounds from aqueous solutions is widely realized with a chemical reaction. They have been produced from aqueous solutions through various technologies. These methods are electrowinning, reduction, segmentation, flotation and the electrolytic extraction process, etc. ${ }^{1-4}$.

Copper sulphites are of considerable interest in chemistry. Precipitation of mixed valence metal sulphates such as copper ammonium sulphite is important to obtain metals. The mixed valence copper sulphite, $\mathrm{Cu}_{2} \mathrm{SO}_{3} \cdot \mathrm{Cu} \mathrm{SO}_{3} \cdot 2 \mathrm{H}_{2} \mathrm{O}, \mathrm{Cu}_{2} \mathrm{SO}_{3} \cdot\left(\mathrm{NH}_{4}\right)_{2} \mathrm{SO}_{3}$ is a model compound characterizing the sulphite structure. This structure indicated that solid metal sulphites and sulphite complexes in solution may play a role as intermediates in various chemical processes. Thus, metal sulphites have been explained as used model compounds in the reactions. For instance, the structures of sulphite ion coordination have strongly influenced the course of the thermal decomposition stable up to $200{ }^{\circ} \mathrm{C}$. At the same time, recovery of the precipitation of this complex compound has formed a key stage in the hydrometallurgical processes $^{5,6}$.

Some studies on the performance of copper ammonium sulphite and the factorial design method in this study were found in the literature. Çolak et al. ${ }^{7}$ precipitated as sulphites to produce copper powders from its impure solutions. Copper(I) sulphate solutions were prepared by utilizing these sulphites. The copper powders were produced by thermal disproportionation of copper(I) sulphate at $60^{\circ} \mathrm{C}$ and $175 \mathrm{~mm}$
$\mathrm{Hg}$ pressure in a nitrogen atmosphere. The copper powders produced were obtained with $99.85 \%$ purity.

Çalban et $_{\text {al }}{ }^{8}$ oxidized copper ore dissolved under optimum conditions using the $2^{\mathrm{n}}$ factorial experimental design and orthogonal central composite design methods in the precipitation experiments. They found that the optimum conditions established for maximum copper precipitation were: temperature $62{ }^{\circ} \mathrm{C}$. $\mathrm{pH} 3$, stirring speed $600 \mathrm{rpm}$ and reaction time $12 \mathrm{~min}$. Fixed parameters chosen at the initial stage of the reaction were: $\mathrm{SO}_{2}$ flow rate $358 \mathrm{~L} \mathrm{~h}^{-1}$ and concentration of $\mathrm{CuSO}_{4}$ solution 7.383 $\mathrm{g} \mathrm{Cu} \mathrm{L}^{-1}$. They founded that the percentage of copper precipitated from leach solution was $99.92^{8}$.

Chevreul's salt precipitated from $\mathrm{CuSO}_{4}$ solutions by means of $\mathrm{Na}_{2} \mathrm{SO}_{3}$. Its appropriate precipitation conditions determined as $\mathrm{pH}-3,\left[\mathrm{SO}_{3}{ }^{2-}\right] /\left[\mathrm{Cu}^{2+}\right]$ ratio- 1.6 , reaction temperature- $60{ }^{\circ} \mathrm{C}$, stirring speed-500 rpm and reaction time-20 min. The precipitate obtained at these conditions contain $49 \%$ copper, with the structure of both tetrahedral coordination of $\mathrm{Cu}(\mathrm{I})$ and octahedral coordination of $\mathrm{Cu}(\mathrm{II})$ in brick red colour 9 .

In another study, the optimum conditions obtained for maximum copper precipitation were: initial solution concentration $1.14 \mathrm{M}, \mathrm{SO}_{2}$ feeding rate $329.35 \mathrm{~L} \mathrm{~h}^{-1}$, reaction time 25 min and initial solution $\mathrm{pH} 8.5$. Under these optimum conditions the percentage of precipitated copper from synthetic aqueous $\mathrm{CuSO}_{4}$ solutions was $99.95^{10}$.

In this study, synthetic copper sulphate was selectively dissolved under optimum conditions in ammonium sulphate solutions. Copper ammonium sulphite was precipitated by 
passing $\mathrm{SO}_{2}$ from these solutions. The $2^{\text {n }}$ factorial experimental design method in the precipitation experiments was used to determine the optimum precipitation conditions. The first model, which relates the copper ammonium sulphite $\left[\mathrm{Cu}_{2} \mathrm{SO}_{3} \cdot\left(\mathrm{NH}_{4}\right)_{2} \mathrm{SO}_{3}\right]$ precipitation yield to process factors was btained. It was characterised by X-ray diffraction.

\section{EXPERIMENTAL}

Factorial design is the most widely used experimental design to estimate the main effects. In a factorial design the influences of all experimental variables, factors and interaction effects on the response or responses are investigated. In addition, the interaction effects are the $2^{\mathrm{n}}$ factorial design, when each variable is investigated at two levels. According to the $2^{\text {n }}$ factorial experimental design method, where the principal steps of experiments are designed, it is often used to obtain firstorder models. If the variance analysis indicates that overall curvature is significant, supportive experiments are carried out to develop a second-order model. The principal steps of experiments are designed: determination of response variables, choice of factor levels and statistical analysis of the data. Consequently, the final step of the work is to obtain a statistically regression model ${ }^{11,12}$.

The main effects and interactions obtained from the regression model are entirely half values obtained from Yates' algoritm. This is due to the response over two levels of each independent variables (from -1 to +1 ). Coded values of variables are high level +1 and low level -1 . Between factor levels, the centre coordinates are zero and that value coincides with the origin of coordinates. A full factorial design was selected to study the influence of the different factors (such as stirring speed, initial concentration, $\mathrm{pH}$ and reaction time).

$$
\hat{\mathrm{Y}}=\mathrm{b}_{0}+\sum_{\mathrm{i}=1}^{4} \mathrm{~b}_{\mathrm{i}} \mathrm{X}_{\mathrm{i}}+\sum_{\mathrm{i}=1}^{\mathrm{n}} \sum_{\mathrm{j}>1}^{\mathrm{n}} \mathrm{b}_{\mathrm{ij}} \mathrm{X}_{\mathrm{i}} \mathrm{X}_{\mathrm{j}}
$$

where the coefficient bishows the main effects of the factors $\mathrm{X}_{\mathrm{i}}, \mathrm{b}_{\mathrm{ii}}$ and $\mathrm{b}_{\mathrm{ij}}$ coefficients represent second-order interaction terms. The independent term $\mathrm{b}_{0}$ represents the response at the zero level of every factor $\left(\mathrm{X}_{1}=\mathrm{X}_{2}=\mathrm{X}_{3}=\mathrm{Xi}=0\right)$.

With four factors, the $2^{4}$ full factorial design requires 16 runs. Furthermore, three central replicates were added to the experimental plan in order to estimate pure experimental error. To test the significance of the factor effects, an analysis of variance was conducted at 95 and $99 \%$ confidence intervals. Furthermore, the effects of pure quadratic terms were controlled by means of the following statistic:

$$
\mathrm{LOF}_{\text {Curv }}=\frac{\mathrm{m}_{0} \mathrm{~F}(1-0)^{2}}{\mathrm{~m}_{0}+\mathrm{F}}
$$

where $\mathrm{m}_{0}$ is the number of central point experiments, $\mathrm{F}$ is the number of factorial experiments, $Y_{1}$ the mean of factorial experiments and $Y_{0}$ is the mean of central replicates ${ }^{13,14}$.

The precipitation process of copper ammonium sulphite was carried out in a glass reactor $(500 \mathrm{~mL})$ with three-necks. Copper solution prepared under the optimum conditions was put into the reactor. The reactor was submerged into a water bath with a digital temperature controller (a MEMMERT ${ }^{\mathrm{TM}}$ ) and the content of reactor was stirred with a water-resistant magnetic stirrer $\left(\mathrm{a} \mathrm{IKA}^{\mathrm{TM}}\right)$. The probe of a WTW ${ }^{\mathrm{TM}} \mathrm{pH}$-meter, which simultaneously measures $\mathrm{pH}$ and temperature was immerged into the solution. The reactor was fitted with a backcooler to prevent loss by evaporation. When the contents of the reactor reached the desired temperature, stirring operation was started at a stable speed, $\mathrm{SO}_{2}$ gas at a stable flowrate was fed into the reactor with a flow-meter until the $\mathrm{pH}$ reached the desired value. Stirring continued along reaction time. At the end of the reaction period, the reactor contents were immediately filtered through Filtrak 389. The chemical structure of precipitated $\mathrm{Cu}_{2} \mathrm{SO}_{3} \cdot\left(\mathrm{NH}_{4}\right)_{2} \cdot \mathrm{SO}_{3}$, with white colour obtained at the end of the first reaction period was characterized by X-ray powder diffraction (Rigaku 2000 JCPDS DMAX (291490) diffractometer (XRD) with $\mathrm{CuK}_{\alpha}$ radiation $(30 \mathrm{kV}$ and $30 \mathrm{~mA}$ and an automatic monochrometer) at a scanning rate

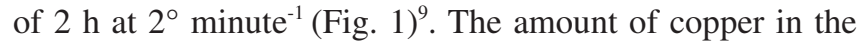
precipitate was determined complexometrically ${ }^{15}$. Then, the factorial experimental design method was used to determine experimental plan.

\section{RESULTS AND DISCUSSION}

Thermodynamic property of copper ammonium sulphite precipitation is related to $\mathrm{pH}$ and initial concentration. In addition, $\mathrm{SO}_{2}$ gas is a versatile reagent capable of precipitating a number of copper sulphates. Some of which can be precipitated selectively from the solution by appropriate adjustments of $\mathrm{pH}$ and initial concentration. Copper ammonium sulphite does not form in acidic solutions containing a considerable amount of sulphurous acid. It is necessary to maintain a $\mathrm{pH}$ range of 3.5-5, because solubility of copper ammonium sulphite increases at lower $\mathrm{pH}$ values.

When copper ammonium sulphite is precipitated from solution, the reactions taking place in the medium can be written as follows ${ }^{9,10,16}$.

$$
\begin{gathered}
10 \mathrm{SO}_{2}(\mathrm{~g})+10 \mathrm{H}_{2} \mathrm{O}(\mathrm{l}) \rightleftharpoons 10 \mathrm{H}_{2} \mathrm{SO}_{3}(\mathrm{aq}) \\
6 \mathrm{Cu}\left(\mathrm{NH}_{3}\right)_{4} \mathrm{SO}_{4}(\mathrm{aq})+10 \mathrm{H}_{2} \mathrm{SO}_{3}(\mathrm{aq})+2 \mathrm{H}_{2} \mathrm{O}(\mathrm{l}) \rightarrow \\
3\left[\mathrm{Cu}_{2} \mathrm{SO}_{3} \cdot\left(\mathrm{NH}_{4}\right)_{2} \mathrm{SO}_{3}\right](\mathrm{s})+9\left(\mathrm{NH}_{4}\right)_{2} \mathrm{SO}_{4}(\mathrm{aq})+\mathrm{SO}_{2}(\mathrm{~g})
\end{gathered}
$$

Statistical analysis of the parameters on copper ammonium sulphite precipitation: In order to determine the optimum conditions and derive a model for acid activation with four factors, a full factorial of the type $2^{4}$ has been used and 16 full factorial design requires 16 runs. Precipitates obtained at all experiments confirmed the generic empirical formula of copper ammonium sulphite. $\mathrm{Cu}_{2} \mathrm{SO}_{3} \cdot\left(\mathrm{NH}_{4}\right)_{2} \mathrm{SO}_{3}$, because of both its white color and chemical analysis results. The precipitates obtained fitted the theoritical copper and sulphur amounts in copper ammonium sulphite. The precipitation tests of copper ammonium sulphite with sulphur dioxide were studied. The collected data were analyzed with an EXEL compatible PC using the ANOVA computer software package for the evaluation of the effect of each parameter on the optimization criteria. Experimental parameters for the precipitation process of synthetic copper sulphate solutions, stirring speed $\left(\mathrm{X}_{1}\right)$, initial concentration $\left(\mathrm{X}_{2}\right), \mathrm{pH}\left(\mathrm{X}_{3}\right)$ and reaction time $\left(\mathrm{X}_{4}\right)$ that were chosen as independent variables to the model, are presented in Table-1. In the light of pre-experiments, two factors; temperature and sulphur dioxide gas flow rate were maintained as constant parameters. Initially, a first-order model 
was chosen to fit the experiment data for the small $\mathrm{F}$ ratio. Experimental data based on the design was fitted to a firstorder polynomial equation as follows:

$$
\hat{\mathrm{Y}}=\mathrm{b}_{0}+\sum_{\mathrm{i}=1}^{\mathrm{n}} \mathrm{b}_{\mathrm{i}} \mathrm{x}_{\mathrm{i}}=\sum_{\mathrm{i}=1}^{\mathrm{n}} \sum_{\mathrm{j}>1}^{\mathrm{n}} \mathrm{b}_{\mathrm{ij}} \mathrm{X}_{\mathrm{i}} \mathrm{X}_{\mathrm{j}}
$$

where the coefficient $b_{i}$ shows the main effects of the factors $X_{i}$ and $b_{i}$ and $b_{i j}$ coefficients represent first-order interactions terms. The independent term $b_{0}$ represents the response at the zero level of every factor $\left(X_{1}=X_{2}=X_{3}=X_{j}=0\right)$.

Furthermore, three central replicates were added to the experimental plan to estimate pure experimental error. To test the significance of the factor effects, an analysis of variance has been conducted at 95 and $99 \%$ confidence intervals. Further- more, the effects of the pure quadratic termswere controlled by means of the following statistic:

$$
\mathrm{LOF}_{\text {Curv }}=\frac{\mathrm{m}_{0} \mathrm{~F}(1-0)^{2}}{\mathrm{~m}_{0}+\mathrm{F}}
$$

where $\mathrm{m}_{0}$ is the number of central point experiments, $\mathrm{F}$ is the number of factorial experiments, is the mean of factorial experiments and is the mean of central replicates. The matrix for four variables is varied at two levels $(+1$ and -1$)$. The higher level of variable was designed as "+" and the lower level was designed as "-". The experiments were usually performed in random order to avoid systematic error. The precipitation of copper ammonium sulphite as $\%$ is presented in Table-2. The results of the analysis of variance are given in Table- 3 .

TABLE-1

FACTOR LEVELS USED IN THE FULL FACTORIAL DESIGN

\begin{tabular}{lccc}
\hline \multicolumn{1}{c}{ Factors } & Low level (-) & High level $(+)$ & Medium level $(0)$ \\
\hline $\mathrm{X}_{1}:$ Stirring speed $(\mathrm{rpm})$ & 700 & 800 & 750 \\
$\mathrm{X}_{2}:$ Initial concentration $(\mathrm{M})$ & 0.4 & 0.8 & 0.6 \\
$\mathrm{X}_{3}: \mathrm{pH}$ & 3.5 & 5 & 4.25 \\
$\mathrm{X}_{4}$ : Reaction time $(\mathrm{min})$ & 15 & 30 & 22.5 \\
\hline
\end{tabular}

TABLE-2

\begin{tabular}{|c|c|c|c|c|c|c|}
\hline Experimental number & $\mathrm{X}_{1}$ & $\mathrm{X}_{2}$ & $\mathrm{X}_{3}$ & $\mathrm{X}_{4}$ & Precipitation yield $\left(\mathrm{Y}_{\mathrm{i}}\right)(\%)$ & $\operatorname{Model}\left(\mathrm{Y}_{\mathrm{Cu}}\right)(\%)$ \\
\hline 1 & 1 & 1 & 1 & 1 & 96.00 & 99.71 \\
\hline 2 & -1 & 1 & 1 & 1 & 98.68 & 94.65 \\
\hline 3 & 1 & -1 & 1 & 1 & 94.81 & 93.42 \\
\hline 4 & -1 & -1 & -1 & 1 & 88.49 & 90.11 \\
\hline 5 & 1 & 1 & -1 & -1 & 95.40 & 91.54 \\
\hline 6 & -1 & 1 & -1 & -1 & 96.25 & 99.80 \\
\hline 7 & 1 & -1 & 1 & -1 & 89.89 & 87.70 \\
\hline 8 & -1 & -1 & 1 & -1 & 88.21 & 90.09 \\
\hline 9 & 1 & 1 & -1 & 1 & 96.19 & 96.47 \\
\hline 10 & -1 & 1 & -1 & 1 & 98.42 & 97.86 \\
\hline 11 & 1 & -1 & -1 & 1 & 87.56 & 85.63 \\
\hline 12 & -1 & -1 & 1 & 1 & 87.82 & 87.67 \\
\hline 13 & 1 & 1 & 1 & -1 & 98.03 & 98.57 \\
\hline 14 & -1 & 1 & 1 & -1 & 98.68 & 99.12 \\
\hline 15 & 1 & -1 & -1 & -1 & 69.94 & 76.12 \\
\hline $1 *$ & 0 & 0 & 0 & 0 & 93.33 & 99.71 \\
\hline $2 *$ & 0 & 0 & 0 & 0 & 93.79 & 94.65 \\
\hline $3 *$ & 0 & 0 & 0 & 0 & 92.84 & 93.42 \\
\hline
\end{tabular}

EXPERIMENTAL DESIGN AND COPPER AMMONIUM SULPHITE PRECIPITATION YIELD

TABLE 3

\begin{tabular}{|c|c|c|c|c|c|c|}
\hline Source of variation & Sum of squares & d.f. & Mean squares & $F$ ratio & Decision $(\alpha=0.05)$ & Decision $(\alpha=0.01)$ \\
\hline $\mathrm{X}_{1}$ & 25.37 & 1 & 25.37 & 112.43 & Effective & Effective \\
\hline $\mathrm{X}_{2}$ & 395.11 & 1 & 395.11 & 1750.62 & Effective & Effective \\
\hline $\mathrm{X}_{3}$ & 50.58 & 1 & 50.58 & 224.13 & Effective & Effective \\
\hline $\mathrm{X}_{4}$ & 25.37 & 1 & 25.37 & 112.43 & Effective & Effective \\
\hline $\mathrm{X}_{1} \mathrm{X}_{2}$ & 3.35 & 1 & 3.35 & 14.87 & Ineffective & Ineffective \\
\hline $\mathrm{X}_{1} \mathrm{X}_{3}$ & 59.40 & 1 & 59.40 & 263.20 & Effective & Effective \\
\hline $\mathrm{X}_{1} \mathrm{X}_{4}$ & 31.50 & 1 & 31.50 & 139.56 & Effective & Effective \\
\hline $\mathrm{X}_{2} \mathrm{X}_{3}$ & 20.67 & 1 & 20.67 & 91.62 & Effective & Ineffective \\
\hline $\mathrm{X}_{2} \mathrm{X}_{4}$ & 20.90 & 1 & 20.90 & 92.63 & Effective & Ineffective \\
\hline $\mathrm{X}_{3} \mathrm{X}_{4}$ & 14.34 & 1 & 14.34 & 63.55 & Effective & Ineffective \\
\hline Curvature & 2.96 & 1 & 2.96 & 13.13 & Ineffective & Ineffective \\
\hline \multirow[t]{2}{*}{ Model lack of fit } & & 5 & 26.89 & 119.16 & Effective & Effective \\
\hline & 295.84 & & & & & \\
\hline Experimental error & 0.45 & 2 & 0.22 & & & \\
\hline
\end{tabular}

ANALYSIS OF VARIANCE 
A first model with interaction terms was chosen to fit the experimental data:

$$
\begin{gathered}
Y=b_{0}+b_{1} X_{1}+b_{2} X_{2}+b_{3} X_{3}+b_{4} X_{4}+b_{5} X_{1} X_{2}+ \\
b_{6} X_{1} X_{3}+b_{7} X_{2} X_{3}+b_{8} X_{2} X_{4}+b_{9} X_{3} X_{4}
\end{gathered}
$$

As seen from Table-3, variance analysis results showed curvature effect. According to these results, the regression firstmodel was obtained as following:

$\% \mathrm{YCu}=92.40-1.25 \mathrm{X}_{1}+4.96 \mathrm{X}_{2}+1.77 \mathrm{X}_{3}+1.25 \mathrm{X}_{4}$

$+0.46 \mathrm{X}_{1} \mathrm{X}_{2}+1.92 \mathrm{X}_{1} \mathrm{X}_{3}+1.40 \mathrm{X}_{1} \mathrm{X}_{4}-1.13 \mathrm{X}_{2} \mathrm{X}_{3}$

$-1.14 X_{2} X_{4}-0.94 X_{3} X_{4}$ (at $95 \%$ confidence interval)

Copper precipitated as copper ammonium sulphite from solution: $(\alpha \geq 0.075)$ (YCu) (\%),

$\% \mathrm{YCu}=92.40-1.25 \mathrm{X}_{1}+4.96 \mathrm{X}_{2}+1.77 \mathrm{X}_{3}+1.25 \mathrm{X}_{4}$

$+1.92 \mathrm{X}_{1} \mathrm{X}_{3}+1.4 \mathrm{X}_{1} \mathrm{X}_{4}$ (at $99 \%$ confidence interval)

As the analysis results of variance quadratic terms are effective. With $\mathrm{F}=16, \mathrm{~m}_{0}=3$ and $\mathrm{n}=4$, according to Eq. (7).
As seen from Eq. (7), copper ammonium sulphite precipitation yield increased with increasing temperature, stirring speed, $\mathrm{pH}$ and reaction time. The ANOVA of the obtained results shows that all of the variables studied and their combinations affect copper ammonium sulphite recovery from aqueous $\mathrm{NH}_{3}-$ $\left(\mathrm{NH}_{4}\right)_{2} \mathrm{SO}_{4}$ solutions. In Table-3, it is possible to identify that copper ammonium sulphite predominates into the initial concentration of the work. Also, in Table-3, the ANOVA results show effect on copper ammonium sulphiterecovery whole parameters. The graphics of tests are presented in Fig. 2a and b).

\section{Conclusion}

The optimum conditions of copper ammonium sulphite recovery from aqueous $\mathrm{NH}_{3}-\mathrm{Cu}\left(\mathrm{NH}_{4}\right)_{2} \mathrm{SO}_{4}$ solutions was investigated. Experiments were designed according to the $2^{\mathrm{n}}$ factorial design method. From the experimental results, the optimal conditions for precipitation of copper ammonium sulphite extent of $99.80 \%$ were obtained as the stirring speed $700 \mathrm{rpm}$,

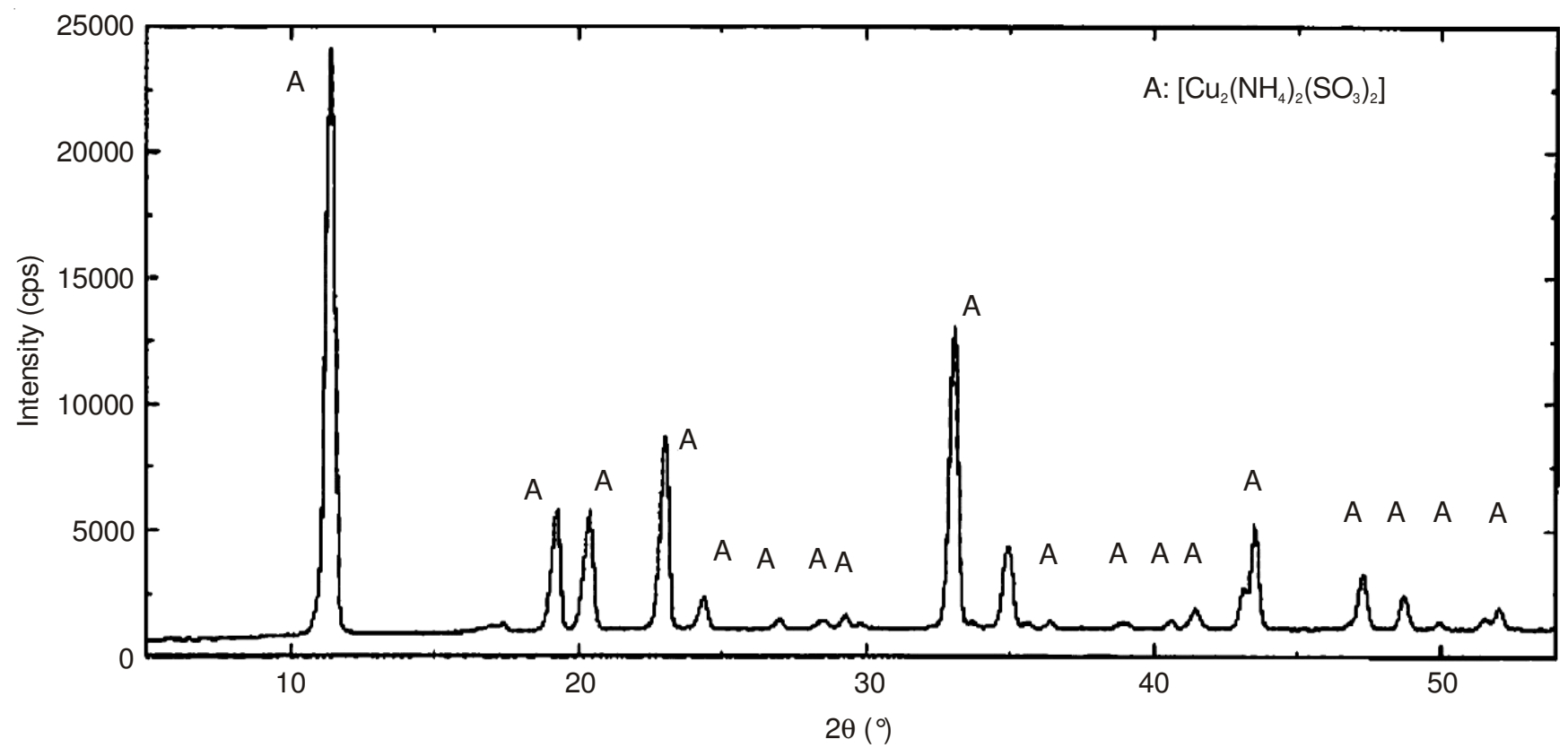

Fig. 1. X-ray diffractogram of $\left[\mathrm{Cu}_{2}\left(\mathrm{NH}_{4}\right)_{2}\left(\mathrm{SO}_{3}\right)_{2}\right]$
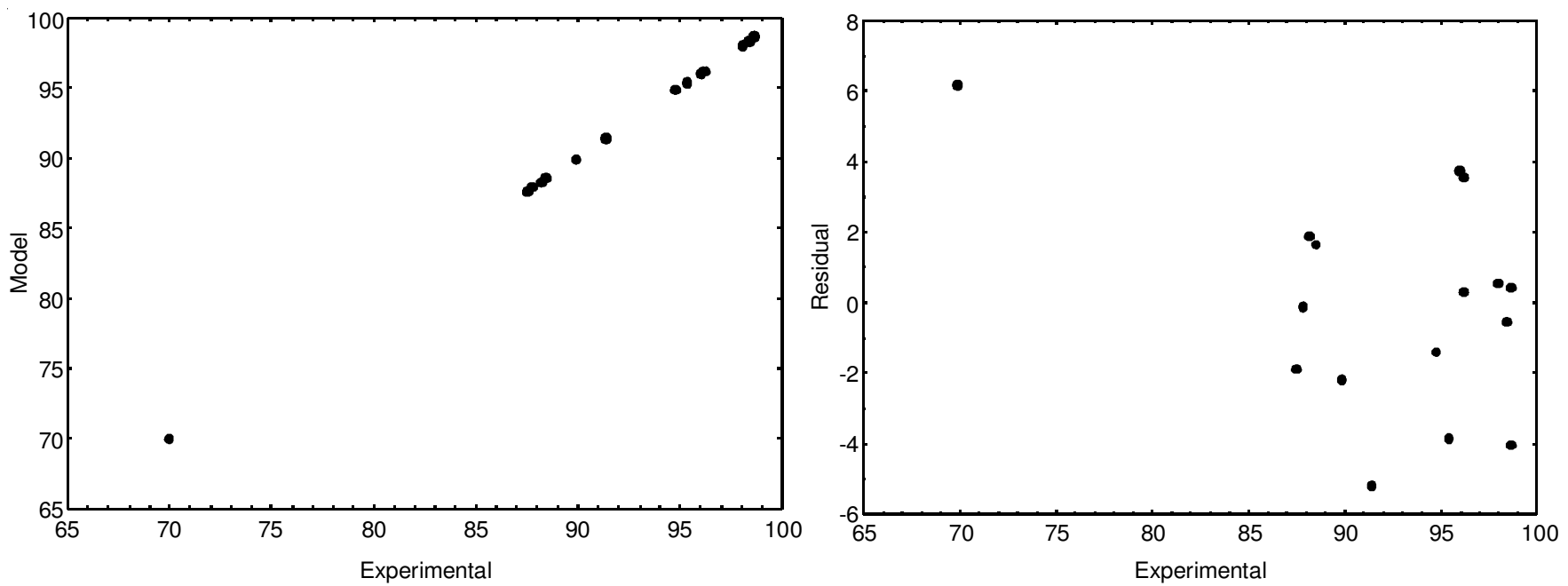

Fig. 2. Statistical test graphics (a and b) 
initial concentration $0.8 \mathrm{M}, \mathrm{pH} 3.5$ and reaction time $15 \mathrm{~min}$. Fixed parameters chosen at the initial stage of the reaction were room temperature $20{ }^{\circ} \mathrm{C}, \mathrm{SO}_{2}$ flow rate was $358 \mathrm{~L} \mathrm{~h}^{-1}$. The correlation coefficient calculated for the first-order model at $92.5 \%$ confidence level has a high value of 0.998 . Therefore, the model supports the experimental data very well. It is very efficient and has no systematic errors. The important parameters affecting the precipitation of copper ammonium sulphite were stirring speed, initial concentration, $\mathrm{pH}$ and reaction time. The recovery of copper ammonium sulphite increased with the increasing stirring speed, initial concentration, $\mathrm{pH}$ and reaction time.

\section{REFERENCES}

1. M. Mohapatra, D. Mishra, S.R. Anand and P. Das, Hydrometallurgy, 58, 193 (2000)

2. M.S. Alam, M. Tanaka, K. Koyama, T. Oishi and J.C. Lee, Hydrometallurgy, 87, 36 (2007)

3. M.H. Abdel-Aziz, Hydrometallurgy, 109, 161 (2011).
4. I.M. Ahmed, Y.A. El-Nadi and J.A. Daoud, Hydrometallurgy, 110, 62 (2011).

5. L.A. Silva, J.R. Matos and J.B. de Andrade, Thermochim. Acta, 360, 17 (2000)

6. K. Nilsson and A. Oskarsson, Acta Chem. Scand., 39A, 663 (1985).

7. S. Çolak, T. Çalban, M. Yesilyurt, D. Sergili and Z. Ekinci, Powder Technol., 134, 65 (2003).

8. T. Çalban, S. Çolak and M. Yesilyurt, Chem. Eng. Process., 45, 168 (2006).

9. M. Yesilyurt and T. Çalban, Inzynieria Chem. Procesowa, 28, 85 (2007).

10. T. Çalban, S. Kuslu and S. Çolak, Chem. Eng. Commun., 196, 1018 (2009).

11. D.C. Montgomery, Design and Analysis of Experiments. John Wiley \& Sons, USA (1976).

12. T. Lundstedt, E. Seifert, L. Abramo, B. Thelin, A. Nyström, J. Pettersen and R. Bergman, Chemom. Intell. Lab. Syst., 42, 3 (1998).

13. E.G. Kirali and O. Laçin, J. Food Eng., 75, 137 (2006).

14. Y. Liang, K. Fang and Q. Xu, Chemom. Intell. Lab. Syst., 58, 43 (2001).

15. H, Gülensoy, Komplexometrinin esaslari ve kompleksometrik titrasyonlar, Fatih Yayinevi, Istanbul, 74, 80 (1984) (in Turkish).

16. C.K.Z. Andrade, O.E. Vercillo, J.P. Rodrigues and D.P. Silveira, J. Braz. Chem. Soc., 15, 813 (2004). 